Xba I sites of pBluescript II KS+. To monitor Hind III cleavage at the site that overlaps the $d A_{10} \cdot T_{10}$ sequence, pBSA10 was cleaved with Bss HII. end-labeled with Klenow and $\left[\alpha^{-32 P}\right] d C T P$, and then cleaved with Kpn I. The 156-bp fragment was purified by polyacrylamide gel electrophoresis (PAGE). To detect Hind III cleavage at the Hind III site that does not overlap the $\mathrm{dA}_{10} \cdot \mathrm{T}_{10}$ site, pBSA10 was digested with Bss HII, endlabeled as above, digested with Sst $I$, and the 167 -bp fragment was purified by PAGE.

11. In some experiments, a small amount of $S 1$ nuclease cleavage was seen on the $A$ strand that mapped to the $3^{\prime}$ end of the $\mathrm{dA}_{10}$ sequence. This reactivity may reflect a slightly strained conformation in the phosphodiester backbone at the junction between the D-loop and double-stranded DNA.

12. PNA. DNA complexes for probing by Hind III were prepared by mixing $0.02 \mathrm{pmol}(\sim 40,000 \mathrm{cpm})$ of the pBSA10 restriction fragment (10) plus 0.5 pmol of Sst I linearized pBSA 10 and incubating with various concentrations of $T_{10}$ Lys in $1 \mathrm{mM}$ tris, $\mathrm{pH} 8.0$, and $0.1 \mathrm{mMEDTA}$ for 1 hour at $37^{\circ} \mathrm{C}$. After the addition of Hind III reaction buffer $(50 \mathrm{mM}$ tris, $\mathrm{pH} 8.0,10 \mathrm{mM}$ $\mathrm{MgCl}_{2}$, and $50 \mathrm{mM} \mathrm{NaCl}$ ) and $10 \mathrm{U}(1 \mu \mathrm{l})$ of Hind III, the reactions (final volume $20 \mu$ l) were incubated for 1 hour at $37^{\circ} \mathrm{C}$ and terminated by the addition of $4 \mu \mathrm{l}$ of $100 \mathrm{mM}$ EDTA. The reaction products were analyzed by a 5\% PAGE, and the bands were visualized by autoradiography. The relative amount of radioactivity in each band was determined with a Molecular Dynamics Phosphorlmager. The percent strand invasion (percent inhibition of Hind III cleavage at the Hind III site overlapping the $d A_{10} \cdot T_{10}$ sequence) was calculated as the percentage of counts in the upper band divided by the total counts of the two bands.

13. We expected that $T_{10}$ Lys, once bound to the DNA, would not dissociate during electrophoresis. Hind III reactions (12) were heated to $90^{\circ} \mathrm{C}$ in the presence of oligomer $\mathrm{dA}_{12}$ (20-fold molar excess of $d A_{12}$ to $\left.P N A\right)$, and gradually cooled to $25^{\circ} \mathrm{C}$. Subsequent PAGE revealed that the Hind III-cleaved restriction fragment migrated at the expected location of $110 \mathrm{bp}$.

14. The plasmids PMLP-10T and PMLP-10A were constructed by cloning a 64-bp fragment, with a $\mathrm{dA}_{10}$ sequence on either the transcribed or nontranscribed strand, respectively, into the Sma I and Hind III sites of pMLP (16). The plasmid PMLP-SV40 was constructed as above except that a 20-bp SV40 T antigen sequence (5'-GAAGAAAAAATGAAGAAAAT) was placed on the transcribed strand.

15. For in vitro transcription reactions with the $T_{10}$ Lys, DNA. PNA complexes were formed by combining 0 to $60 \mathrm{pmol}$ of PNA with $0.09 \mathrm{pmol}(0.2 \mu \mathrm{g})$ of pMLP plasmid plus $0.39 \mathrm{pmol}(0.8 \mu \mathrm{g})$ of promotor-minus plasmid (16) in $1 \mathrm{mM}$ tris, $\mathrm{pH} 8.0$, and $0.1 \mathrm{mM}$ EDTA and incubating for $1 \mathrm{hour}$ at $37^{\circ} \mathrm{C}$ in a total volume of $9 \mu \mathrm{l}$. In vitro transcription was initiated as described (17) with $4 \mu$ l of a rat hepatocyte nuclear extract in a total volume of 20 $\mu /$ and incubated at $30^{\circ} \mathrm{C}$ for $40 \mathrm{~min}$. For in vitro transcription reactions with the SV40 15-mer PNA, 0 to 150 pmol of PNA were incubated with 0.09 pmol $(0.2 \mu \mathrm{g})$ of pMLP plasmid in $1 \mathrm{mM}$ tris, $\mathrm{pH}$ 8.0 , and $0.1 \mathrm{mM}$ EDTA for $1 \mathrm{hour}$ at $37^{\circ} \mathrm{C}$ in a total volume of $9 \mu \mathrm{l}$. In vitro transcription was initiated as described (16) with $3 \mu$ l of a HeLa nuclear extract (Promega) in a total volume of $25 \mu \mathrm{l}$ and incubated at $30^{\circ} \mathrm{C}$ for $40 \mathrm{~min}$. [32P]UTP RNA transcripts were analyzed by 5 to $6 \%$ denaturing PAGE.

16. M. Sawadogo and R. G. Roeder, Proc. Natl. Acad Sci. U.S.A. 82, 4394 (1985).

17. K. Gorski, M. Carneiro, U. Schibler, Cell 47, 767 (1986)

18. RNA containing the $r A_{10}$ sequence was obtained by incubating $2 \mu \mathrm{g}$ of Pvu II-linearized pBSA10 with $0.4 \mathrm{mM}$ ribonucleotide $5^{\prime}$-triphosphates, 30 $\mathrm{mM}$ dithiothreitol (DTT), $80 \mathrm{U}$ of RNasin, and $20 \mathrm{U}$ of T3 RNA polymerase in T3/T7 buffer ( $40 \mathrm{mM}$ tris pH 7.5, $50 \mathrm{mM} \mathrm{NaCl}, 8 \mathrm{mM} \mathrm{MgCl}$, and $2 \mathrm{mM}$ spermidine) for $30 \mathrm{~min}$ at $37^{\circ} \mathrm{C}$. Deoxyribonuclease I was added, followed by phenol-chloroform ex-

traction and ethanol precipitation. RNA containing the $U_{10}$ sequence was obtained as above, except that T7 RNA polymerase was used.

19. RNA - ODN primer complexes for RT were prepared by combining $0.5 \mu \mathrm{g}$ of RNA (18) and $125 \mathrm{ng}$ of ODN (M13-20 primer or reverse primer) to a final volume of $10 \mu \mathrm{l}$, heating to $70^{\circ} \mathrm{C}$ for $10 \mathrm{~min}$, and then placing the solution on ice. Hybridization of PNA to the RNA $\cdot$ ODN mixtures was performed at $37^{\circ} \mathrm{C}$ by the addition of $1 \mu \mathrm{l}$ of PNA ( 0 to $1 \mu \mathrm{M}$ final concentrations), $4 \mu$ l of $5 \times$ buffer ( $250 \mathrm{mM}$ tris, pH 8.3, 375 $\mathrm{mM} \mathrm{KCl}$, and $15 \mathrm{mM} \mathrm{MgCl}$ ), $2 \mu \mathrm{l}$ of $100 \mathrm{mM}$ DTT, and $1 \mu l(40 \mathrm{U})$ of RNasin. After $20 \mathrm{~min}, 1 \mu \mathrm{l}$ of a solution of deoxyribonucleotide $5^{\prime}$-triphosphates (dNTPs) $\{10 \mathrm{mM}$ of dGTP, TTP, and dCTP, $0.1 \mathrm{mM}$ dATP, and $10 \mu C i$ of $\left.\left[\alpha^{-32 P}\right] d A T P\right\}$ was added and the reaction initiated by the addition of $1 \mu l(200 \mathrm{U})$ of Superscript RNase $\mathrm{H}^{-}$MMLV reverse transcriptase (BRL). After a 15-min incubation, $1 \mu \mathrm{l}$ of $10 \mathrm{mM}$ dATP was added and after an additional $15 \mathrm{~min}$ the reaction was terminated by $4 \mu \mathrm{l}$ of $0.5 \mathrm{M}$ EDTA, phenol-chloroform extraction, and ethanol precipitation. The samples were analyzed by $6 \%$ denaturing PAGE

20. Plasmid PGEM-IL2R-SV40, containing a $\mathrm{d}\left(\mathrm{A}_{3} \mathrm{TGA}_{2} \mathrm{GA}_{2}\right)$ segment on the coding strand, was constructed by cloning a 33-bp duplex into the Nde I site of pGEM-IL2R3 (gift of W. C. Greene) (21).

21. W. J. Leonard et al., Nature 311, 626 (1984)

22. RNA for in vitro translation was prepared from $X$ ba I-digested PGEM-IL2R3, Xba l-digested PGEMIL2R-SV40, or Nde I-digested pGEM-IL2R3 as previously described (23). RNA $(0.5 \mu \mathrm{g})$ and PNA ( 0 to $50 \mathrm{pmol}$ ) were mixed on ice with $20 \mu \mathrm{M}$ amino acid mixture (minus Met), $2 \mathrm{mM}$ DTT, $20 \mathrm{U}$ of RNasin, $80 \mathrm{mM} \mathrm{KCl}, 1 \mu \mathrm{l}$ of [ ${ }^{35}$ S]Met $(1100$ $\mathrm{Ci} / \mathrm{mmol}, 10 \mathrm{mCi} / \mathrm{ml})$, and $16.5 \mu \mathrm{l}$ Promega Flexi Rabbit Reticulocyte Lysate in a total reaction volume of $25 \mu \mathrm{l}$. Incubations were performed at $30^{\circ} \mathrm{C}$ for 1 hour and were terminated by boiling for $3 \mathrm{~min}$ in $62.5 \mathrm{mM}$ tris- $\mathrm{HCl}, \mathrm{pH} 6.8,10 \%$ glycerol, $2 \%$ SDS, and $5 \% \beta$-mercaptoethanol. The samples were analyzed by $12 \%$ SDS-PAGE.

23. D. E. Titus, Ed., Promega Protocols and Applications Guide (Promega, Madison, WI, ed. 2, 1991), pp. $59-61$

\title{
Dual-Target Inhibition of HIV-1 in Vitro by Means of an Adeno-Associated Virus Antisense Vector
}

\author{
Saswati Chatterjee," Philip R. Johnson,† K. K. Wong, Jr.‡
}

An adeno-associated virus vector encoding an antisense RNA was used to transduce stable intracellular resistance to human immunodeficiency virus-1 (HIV-1) in human hemopoietic and non-hemopoietic cell lines. The antisense targets are present in all HIV-1 transcripts and include the TAR sequence, which is critical for transcription and virus replication, and the polyadenylation signal. Cell lines expressing antisense RNA showed up to 95 percent inhibition of gene expression directed by the HIV-1 long terminal repeat and greater than 99 percent reduction in infectious HIV-1 production, with no detectable cellular toxicity. Because of their efficient transcription and inability to recombine with HIV-1, adeno-associated virus vectors represent a promising form of anti-retroviral gene therapy.

Current estimates indicate that more than 1 million people in the United States may be infected with HIV-1, a causative agent of acquired immunodeficiency syndrome (AIDS) (1). One potential form of gene therapy for AIDS is based on the concept of intracellular immunization, the induced expression of molecules that block HIV gene transcription or translation (2). Molecules with potential HIV inhibitory activity in- clude the trans-dominant proteins derived from viral rev (3) and gag genes (4) and ribozymes targeted to transcripts of the gag (5) and integrase genes (6) and to the $5^{\prime}$ leader RNA (7). Antisense RNAs may also be used to block HIV-1 infection, although the success of this approach thus far has been limited by inefficient expression and poor target selectivity (8). In many of these experiments, the antisense RNAs were ex- 
pressed in retroviral vectors as part of long transcripts from RNA polymerase II-dependent promoters. The length of the transcripts may have contributed to inefficient targeting (9).

We have designed a new antisense strategy for HIV-1 that targets a long terminal repeat (LTR) sequence present at both the $5^{\prime}$ and $3^{\prime}$ ends of all HIV-1 transcripts. A high-efficiency transducing vector, adenoassociated virus (AAV), was used for the delivery of the antisense gene. AAV has a linear single-stranded DNA genome of 4.6 $\mathrm{kb}$ with palindromic inverted terminal repeats (ITRs). AAV is replication-defective; that is, coinfection with a helper virus, such as adenovirus, is required for productive infection (10). Molecular clones of the AAV genome are infectious after transfection into helper virus-infected cells (11).

AAV vectors have high transduction frequencies $(12,13)$ in cells of diverse lineages, including hemopoietic cells (14, $15)$. In the absence of helper virus, wildtype AAV integrates via the ITRs in a presumably site-specific manner into human chromosome $19 q(16)$. The absence of endogenous promoter activity in AAV vectors permits efficient expression of short antisense transcripts, leading to better targeting of HIV-1 RNA. In addition, unlike retroviral vectors, AAV vectors cannot generate new retroviral pseudotypes by recombination with HIV-1 (17) or create insertional mutants by random integration.

The AAV vector in this study encoded a selectable marker, the bacterial neomycin resistance gene $\left(\mathrm{Neo}^{\mathrm{R}}\right)$ and a constitutively transcribed HIV-1-specific antisense RNA. The target for the antisense RNA is encoded in the HIV-1 LTR and is therefore represented twice in the HIV-1 genome and in all HIV-1 mRNAs. Specifically, the antisense RNA was complementary to: (i) bases +13 to +75 within the $5^{\prime}$ untranslated leader sequence of $\mathrm{pHXB2}$ [an infectious molecular clone of HIV-1 (18)], a stretch that includes

S. Chatterjee, Laboratory of Viral Diseases, National Institute of Allergy and Infectious Diseases (NIAID), National Institutes of Health (NIH), and Division of Molecular Virology and Immunology, Department of Microbiology, Georgetown University, Rockville, MD 20852.

P. R. Johnson, Laboratory of Infectious Diseases, NIAID, NIH, and Division of Molecular Virology and Immunology, Department of Microbiology, Georgetown University, Rockville, MD 20852.

K. K. Wong, Jr., Laboratory of Viral Diseases, NIAID, NIH, Rockville, MD 20852.

*To whom correspondence should be addressed at Division of Pediatrics, City of Hope National Medical Center and Department of Molecular Genetics, Beckman Research Institute of the City of Hope, Duarte, CA 91010.

tPresent address: Children's Hospital, The Ohio State University, Columbus, OH 43205.

†Present address: Department of Hematology/Bone Marrow Transplantation, City of Hope National Medical Center, Duarte, CA 91010. the TAR sequence, a cis-acting RNA stemloop structure whose interaction with the HIV-1-encoded Tat protein is essential for virus transcription and replication (19); and (ii) bases 9096 to 9160 within the common $3^{\prime}$ end of all HIV-1 mRNAs, including part of the polyadenylation signal (bases 9158 through 9163) (Fig. 1).

To determine the efficacy of the antisense
RNA in a single round of HIV-1 replication, we initially transfected the antisense vector into CD4- 293 cells, a human embryonic kidney cell line transformed by adenovirus type $5 E 1 A$ and E1B (20), and isolated G418-resistant colonies. Antisense RNA expression was assayed by Northern (RNA) blot analysis. The antisense transcripts ranged in size from 0.7 to $1 \mathrm{~kb}$, depending
Fig. 1. Map of the AAV vector encoding recombinant HIV-LTR antisense RNA. The vector (pCWRSVNHIVA) was constructed by removing all endogenous coding sequences (bases 190 to 4034) from an infectious molecular clone of AAV (pAV1) (11) and inserting the RSV LTR, a cloning site polylinker, and the $\mathrm{NeO}^{R}$ gene under control of the SV40 early promoter. Ar-

rows indicate the direction of transcription from the SV40 and RSV promoters. Also shown are the complementary synthetic oligodeoxynucleotides cloned downstream of the RSV LTR, the predicted sequence of the antisense RNA transcript, and the target sequence in the $5^{\prime}$ and $3^{\prime}$ untranslated regions of HIV-1 RNA.
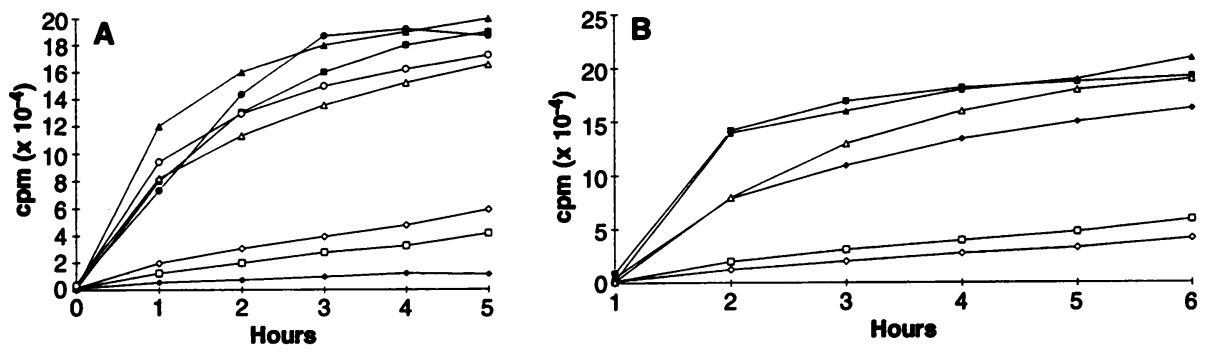

Fig. 2. Inhibition of HIV-1 LTR-directed gene expression and virus replication in $\mathrm{CD}^{-}$antisense clones. (A) CAT activity was measured by a fluor diffusion assay (29) in lysates of Alpha 1, Alpha 2, IIC4, and 293 cells 48 hours after transfection with either 3 $\mu \mathrm{g}$ of E2-CAT or $3 \mu \mathrm{g}$ of pBennCAT plus $1 \mu \mathrm{g}$ of PAR by calcium phosphate coprecipitation.

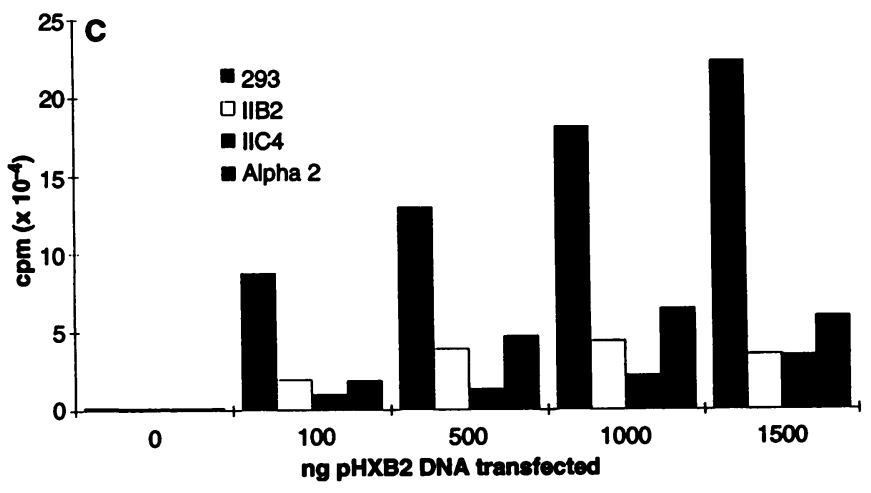

1. HIVCAT activity in 293 cells; $\square$, HIVCAT activity in IIC4 cells; HIVCAT activity in Alpha 2 cells; $\diamond$, HIVCAT activity in Alpha 1 cells; $\Delta$, E2-CAT activity in 293 cells; $\triangle$, E2-CAT activity in IIC4 cells; - E2-CAT activity in Alpha 2 cells; and O, E2-CAT activity in Alpha 1 cells. E2-CAT was generated by cloning a Sau 3A fragment from pKCAT23 (30), which contains the CAT gene under control of the adenovirus type $5 \mathrm{E} 2$ promoter, into the AAV vector. (B) CAT activity 48 hours after transfection of cells with either $3 \mu \mathrm{g}$ of RSV-CAT or $3 \mu \mathrm{g}$ of pBennCAT plus $1 \mu \mathrm{g}$ of pAR. $\square$, RSVCAT activity in Alpha 1 cells; $\square$, HIVCAT activity in Alpha 1 cells; $\diamond$ RSVCAT activity in IIC4 cells; $\diamond$. HIVCAT activity in IIC4 cells; $\Delta$, RSVCAT activity in 293 cells; and $\triangle$. HIVCAT activity in 293 cells. RSV-CAT was generated by inserting the CAT gene in the AAV vector containing the RSV LTR. Transcripts from both RSV-CAT and E2-CAT used the endogenous AAV polyadenylation signal. (C) IIB2, IIC4, Alpha-2, and 293 cells $\left(1.5 \times 10^{6}\right)$ were transfected with 100 to $1500 \mathrm{ng}$ of pHXB2 DNA (and $3 \mu \mathrm{g}$ of E2-CAT as carrier), and the culture supernatant $(20 \mu l)$ was assayed for RT activity (31) 3 days after transfection. CAT assays performed on cell lysates revealed less than $10 \%$ variation between the clones, indicating equivalent transfection efficiencies. 
upon the extent of polyadenylation, and were present in substantially higher amounts than actin mRNA (21).

To examine the effect of the HIV-1 antisense RNA on HIV-1 LTR-directed gene expression, we cotransfected parental 293 cells and 35 antisense-expressing clones with two plasmids, one encoding the chloramphenicol acetyl transferase (CAT) gene driven by the HIV-1 LTR (pBennCAT) (22) and the other encoding the first exon of Tat, also under HIV-1 LTR control (pAR) (22). CAT expression (HIVCAT) required both expression of $\mathrm{Tat}$ and its interaction with TAR in the HIV-1 LTR. All antisense clones tested demonstrated a diminution (up to 95\%) of HIV-1 LTRdirected CAT expression. In contrast, no diminution of CAT activity was observed in cells expressing CAT under the control of two heterologous promoters, the adenovirus E2 promoter (Fig. 2A) or the Rous sarcoma virus (RSV) LTR (Fig. 2B), indicating that the inhibition was specific for the HIV-1 LTR. Similar levels of CAT activity were observed in the parental cells and in the antisense clones with the heterologous promoters, indicating that the transfection efficiencies were similar in all cell lines tested.

We assayed three clones for HIV-1 virus production after a single round of replication by measuring reverse transcriptase (RT) activity in culture supernatants 3 days after transfection with $\mathrm{pHXB2}$. Virus replication in all three clones was reduced by 70 to $90 \%$ compared to that in the control 293 cells (Fig. 2C), and this effect was independent of the amount of transfected HIV-1 plasmid DNA. Inhibition of virus production was evident 1 day after transfection and remained maximal from days 2 through 8 , the last day tested.

To investigate the specificity of inhibition, we transfected parental 293 cells and two antisense-expressing clones with an infectious proviral DNA (pSMMH4i) of simian immunodeficiency virus (SIV), a related but genetically distinct primate lentivirus. SIV production was inhibited in the antisense-expressing clones, but to a lesser degree than was HIV-1 production (86 and $73 \%$ inhibition of SIV in clones IIC4 and Alpha 1, respectively, at day 3 after transfection, as compared to 91 and $86 \%$ inhibition of HIV-1). Inhibition of SIV production in the HIV-1 antisense-expressing clones was probably due to the sequence similarity of the SIV and HIV-1 TARs (23). Replication of an unrelated virus, herpes simplex virus-1, was not affected by the HIV-1 antisense sequence (24).

To determine the mechanism of HIV-1 inhibition, we analyzed the expression of HIV-1 RNA in pHXB2-transfected 293 cells and in one antisense clone, IIC4, by

A

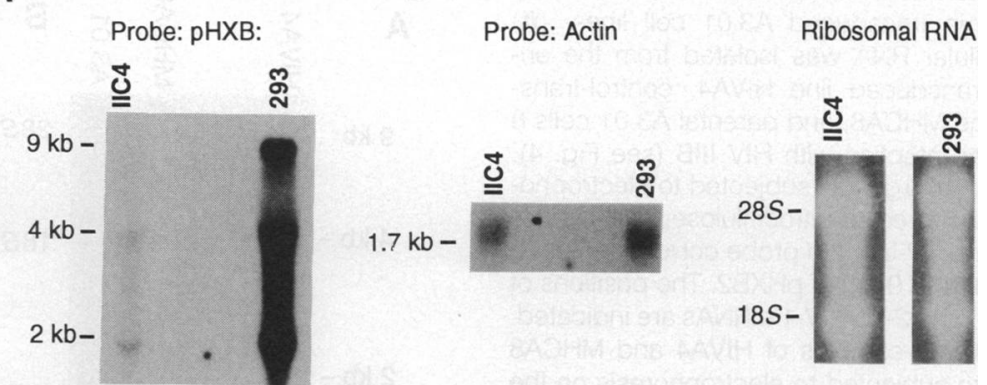

Fig. 3. Inhibition of HIV RNA accumulation in antisense clones. (A) Total cellular RNA was extracted from IIC4 (lane 1) and 293 (lane 2) cells 4 days after transfection with $100 \mu \mathrm{g}$ of pHXB2 (and $3 \mu \mathrm{g}$ of E2-CAT as carrier). The RNA was subjected to electrophoresis in a $1 \%$ agarose-formaldehyde gel in 4-morpholinepropanesulfonic acid buffer, transferred to nitrocellulose, and hybridized with a ${ }^{32}$ P-labeled probe corresponding to bases 8141 to 9615 of pHXB2. The positions of the 9,4 , and $2 \mathrm{~kb}$ HIV-1 mRNAs are indicated. Transfection efficiencies were controlled as before. (B) The pHXB2 probe was washed off and the blot rehybridized with an actin probe. The reduction of the actin mRNA signal in IIC4 relative to 293 cells (41\% reduction versus a 92 to $97 \%$ reduction of the HIV-1 mRNA signals) may have resulted from the washing procedure prior to reprobing for actin mRNA. (C) Ethidium bromide-stained gel prior to RNA transfer and hybridization (in A and B). The positions of $28 S$ and $18 S$ ribosomal RNAs from IIC4 (lane 1) and 293 (lane 2) cells are indicated.

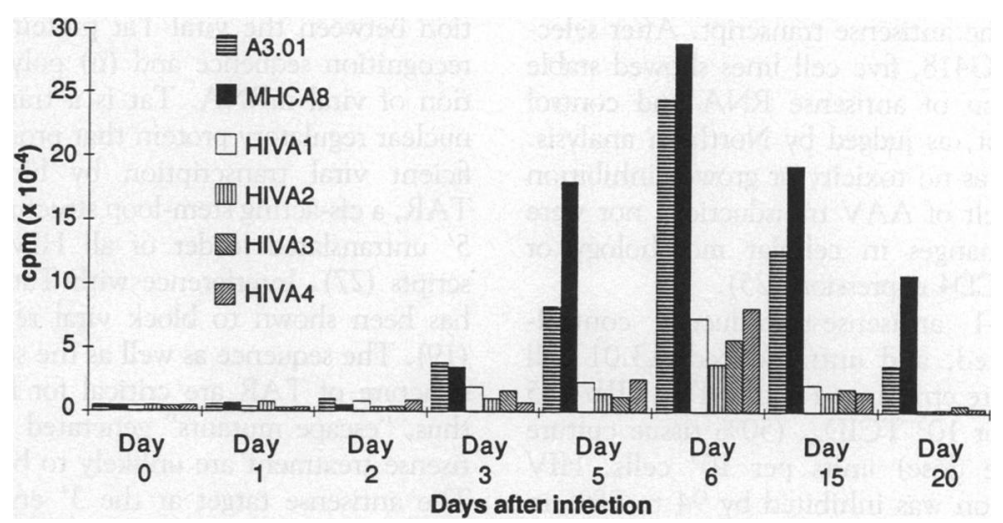

Fig. 4. Inhibition of HIV-1 IIIB replication in antisense-transduced cells. Antisense-transduced (HIVA1, HIVA2, HIVA3, and HIVA4), control-transduced (MHCA8), and parental A3.01 cells (105 cells per sample) were challenged with $10^{5} \mathrm{TCID}_{50}$ units of HIV-1 IIIB. Virus replication was measured by quantitating RT activity in culture supernatants at various times after viral challenge. The $y$-axis shows RT activity in counts per minute per milliliter per $10^{6}$ cells.

Northern blots. All three major HIV-1 RNA species $(9,4$, and $2 \mathrm{~kb})$ were readily detected in 293 cells (Fig. 3A), but only low amounts of HIV-1 RNA were detected in IIC4 cells. Furthermore, when HIV-1 RNA was present, no antisense RNA was detected in the IIC4 cells, suggesting that double-stranded sense:antisense RNA hybrids were rapidly degraded. Thus, clones expressing HIV-1 antisense RNA inhibited the accumulation of HIV-1 mRNA.

We next examined the ability of an encapsidated viral stock of the antisense vector to transduce HIV-1 resistance to a human $\mathrm{T}$ lymphocyte line in culture. Our initial immunofluorescence experiments with antibodies to AAV, as well as previously reported results (15), showed that wildtype AAV could indeed infect human $\mathrm{CD}^{+}$ $T$ lymphocyte lines. Infectious stocks of the HIV-1 antisense-encoding AAV vector were generated by cotransfecting adenovirus-infected HeLa cells with the antisense AAV vector plasmid and a helper plasmid (pTAAV, containing bases 321 through 4489 of the AAV genome) that provided AAV replication and encapsidation functions, but not the ITRs or encapsidation signal. The recombinant vector was then passaged a second time on adenovirus-infected, cotransfected HeLa cells. The titer of the resultant recombinant AAV stock was $10^{7}$ transducing units per milliliter, as determined by enumeration of G418-resistant colonies. Quantitative Southern analysis of the recombinant viral DNA revealed $<0.1 \%$ wild-type AAV contamination.

To investigate whether the antisense vector could confer HIV-1 resistance to CD4 ${ }^{+}$ lymphocytes, we transduced A3.01 cells (a clone of the CEM human T lymphoblastoid line that expresses high concentrations of 
Fig. 5. Northern analysis of HIV mRNA accumulation in transduced A3.01 cell lines. (A) Total cellular RNA was isolated from the antisense-transduced line HIVA4, control-transduced line MHCA8, and parental A3.01 cells 6 days after infection with HIV IIIB (see Fig. 4). The RNA $(15 \mu \mathrm{g})$ was subjected to electrophoresis, transferred to nitrocellulose, and hybridized with a ${ }^{32} \mathrm{P}$-labeled probe corresponding to bases 8141 to 9615 of pHXB2. The positions of the 9-, 4-, and 2-kb HIV-1 mRNAs are indicated. (B) Duplicate samples of HIVA4 and MHCA8 RNA were subjected to electrophoresis on the same gel as in (A). These lanes were stained with ethidium bromide. The positions of $28 \mathrm{~S}$ and $18 S$ ribosomal RNAs are shown.

CD4) with four separate HIV-1 antisense AAV vector stocks (to determine the reproducibility of the results), and with an unrelated AAV vector as a control for the transduction and G418 selection procedures. The control transcript was not complementary to HIV-1 or cellular RNA but was similar in size to the antisense transcript. After selection in G418, five cell lines showed stable expression of antisense RNA and control transcript, as judged by Northern analysis. There was no toxicity or growth inhibition as a result of AAV transduction, nor were there changes in cellular morphology or surface CD4 expression (25).

HIV-1 antisense-transduced, controltransduced, and untransduced A3.01 cell lines were challenged with HIV-1 IIIB at 5 $\times 10^{3}$ or $10^{5} \mathrm{TCID}_{50}(50 \%$ tissue culture infective dose) units per $10^{5}$ cells. HIV replication was inhibited by 94 to $98 \%$ in all four antisense vector-transduced lines at both multiplicities of infection tested (Fig. 4) and for over a period of 20 days. Northern analysis of one of the antisense lines, HIVA4 (Fig. 5), revealed that these cells expressed much lower amounts of the major HIV-1 mRNA species, compared to the control-transduced line (MHCA8) or parental A3.01 cells. This result again demonstrates that cells expressing antisense RNA do not accumulate HIV-1 mRNA. The absence of detectable antisense RNA upon HIV-1 infection suggests that the HIV-1 inhibition may be due to ribonuclease-mediated degradation or physical modification of double-stranded RNA.

We next determined the titer of infectious virus in the culture supernatants of the parental A3.01 cells and two transduced cell lines, HIVA4 and MHCA8, after challenge with HIV-1. Culture supernatants collected from the three cell lines 20 days after HIV- 1 infection were titered on indicator CEM cells by the HIV infectivity assay (26). A3.01 and MHCA8 cells produced HIV-1 at a titer of $10^{4} \mathrm{TCID}_{50}$ units per milliliter, whereas HIVA4 cells produced $10 \mathrm{TCID}_{50}$ units of HIV-1 per milliliter. This represents

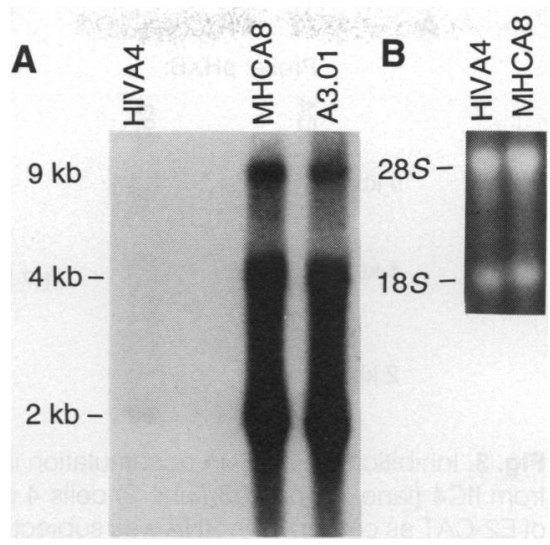

a $99.99 \%$ reduction in infectious virus. A similar inhibition of HIV-1 production was observed in $\mathrm{H} 9$ cells, another $\mathrm{CD} 4^{+}$human cell line, after transduction of HIV-1 antisense sequences (21).

Our antisense strategy targeted two critical steps in the HIV-1 life cycle: (i) interaction between the viral Tat protein and its recognition sequence and (ii) polyadenylation of viral mRNA. Tat is a trans-acting nuclear regulatory protein that promotes efficient viral transcription by binding to TAR, a cis-acting stem-loop structure in the $5^{\prime}$ untranslated leader of all HIV-1 transcripts (27). Interference with Tat binding has been shown to block viral replication (19). The sequence as well as the secondary structure of TAR are critical for function; thus, "escape mutants" generated after antisense treatment are unlikely to be viable. The antisense target at the $3^{\prime}$ end of the HIV-1 RNAs may provide a secondary trap for any viral $\mathrm{mRNAs}$ that have escaped the TAR-mediated blockade, and may also disrupt polyadenylation, which would lead to destabilization of the viral mRNAs. Because the target sequences in the LTR are highly conserved among HIV-1 isolates, this antisense strategy may confer broad resistance against genetically diverse HIV-1 strains. Notably, the intracellular expression of the antisense RNA showed a comparable effect on HIV-1 replication regardless of whether the vector was introduced through plasmid transfection or AAV transduction.

$\mathrm{AAV}$ is a nonpathogenic virus that can transduce diverse cells including those of human and simian origin. Multiple copies of the vector integrate into cellular DNA in a tandem fashion (13). AAV does not prevent superinfection (28), a property that allows for infection with several different vectors or multiple rounds of infection with the same vector. $A A V$ therefore appears to be an ideal vector for use in antiretroviral gene therapy.

For the treatment of human AIDS, it may be necessary to confer intracellular resistance to progenitor bone marrow cells that give rise to the renewable targets $(T$ lymphocytes, monocytes, and macrophages) of HIV-1 infection. Autologous AAV vector-transduced bone marrow stem cells could then be used to repopulate the immune system with HIV-resistant cells. This treatment strategy will best be evaluated in animal models, such as SIV-infected non-human primates. If AAV vectors are safe and efficacious in this setting, human trials may be indicated.

\section{REFERENCES AND NOTES}

1. J. A. Wiley and M. C. Samuel, AIDS (Phila.) 3 (suppl. 1), S71 (1989).

2. D. Baltimore, Nature 335, 395 (1988); I. Herskowitz, ibid. 329, 219 (1987); A. D. Friedman, S. J. Triezenberg, S. L. McKnight, ibid. 335, 452 (1988); T. R. Cech and B. Bass, Annu. Rev. Biochem. 55, 599 (1986).

3. M. H. Malim, S. Bohnlein, J. Hauber, B. R. Cullen, Cell 58, 205 (1989); T. J. Hope et al., J. Virol. 66, 1849 (1992)

4. D. Trono et al., Cell 59, 113 (1989).

5. N. Sarver et al., Science 247, 1222 (1990).

6. M. Sioud and K. Drlica, Proc. Natl. Acad. Sci. U.S.A. 88, 7303 (1991).

7. M. Weerasinghe et al., J. Virol. 65, 5531 (1991).

8. A. Rhodes and W. James, J. Gen. Virol. 71, 1965 (1990); S. Joshi et al., J. Virol. 65, 5524 (1991).

9. T. Shimada et al., Antiviral Chem. Chemother. 2 , 133 (1991); B. A. Sullenger et al., Mol. Cell. Biol. 10, 6512 (1990).

10. K. I. Berns and R. A. Bohenzky, Adv. Virus Res. 32, 243 (1987).

11. R. J. Samulski, K. I. Berns, M. Tan, N. Muzyczka, Proc. Natl. Acad. Sci. U.S.A. 79, 2077 (1982); C. A. Laughlin, J.-D. Tratschin, H. Coon, B. J. Carter, Gene 23, 65 (1983).

12. P. Hermonat and N. Muzyczka, Proc. Natl. Acad. Sci. U.S.A. 81, 6466 (1984).

13. S. K. McLaughlin, P. Collis, P. L. Hermonat, N. Muzycka, J. Virol. 62, 1963 (1988)

14. D. Laface, P. Hermonat, E. Wakeland, A. Peck, Virology 162, 483 (1988).

15. E. Mendelson, Z. Grossman, F. Mileguir, G. Rechavi, B. J. Carter, ibid. 187, 453 (1992).

16. R. M. Kotin et al., Proc. Natl. Acad. Sci. U.S.A. 87, 2211 (1990).

17. P. Lusso et al., Science 247, 848 (1990).

18. L. Ratner et al., AIDS Res. Hum. Retroviruses 3, 57 (1987).

19. B. R. Cullen and W. C. Greene, Cell 58, 423 (1989).

20. F. L. Graham, Virology 52, 456 (1977)

21. S. Chatterjee and K. K. Wong, unpublished data.

22. H. E. Gendelman et al., Proc. Natl. Acad. Sci. U.S.A. 83, 9759 (1986).

23. R. Fenrick et al., J. Virol. 63, 5006 (1990).

24. K. K. Wong, unpublished data.

25. Cell counts performed on transduced cells over a period of 56 days indicated no differences from the parental line. Cytofluorometric analysis revealed normal amounts of CD4 on transduced cells.

26. A. Aldovini and B. D. Walker, Eds., Techniques in HIV Research (Stockton, New York, 1990)

27. S. Feng and E. C. Holland, Nature 334, 165 (1988).

28. J. S. Lebkowski et al., Mol. Cell. Biol. 8, 3988 (1988)

29. E. M. Neumann et al., BioTechniques 5, 444 (1987).

30. D. L. Weeks and N. C. Jones, Mol. Cell. Biol. 3, 1222 (1983)

31. S. Goldstein et al., J. Acquired Immune Defic. Syndr. 3, 98 (1990).

32. We thank B. Moss for encouragement and scientific critique; J. Rose for support; V. Hirsch. J. Zaia, and $\mathrm{J}$. Rossi for manuscript review and many helpful comments; and S. Kitov for RT assays.

4 June 1992; accepted 2 October 1992 